\title{
REQUERIMIENTOS Y POSIBILIDADES PARA LA ADMINISTRACIÓN DE RIESGOS DE PRECIOS DEL ARROZ EN COLOMBIA ${ }^{1}$
}

\author{
REQUIREMENTS AND POSSIBILITIES FOR MANAGING \\ RICE PRICE RISK IN COLOMBIA
}

\author{
Álvaro Ramírez Suárez² y Ernesto Martínez Vargas $^{3}$
}

\begin{abstract}
Resumen
Este artículo documenta la magnitud y tendencias de las fluctuaciones de precios del arroz en Colombia a través de los eslabones de la cadena de valor. Así mismo, explora las posibilidades de introducir estrategias y mecanismos, tanto a nivel de empresa como basados en el mercado bursátil, para la administración de riesgos de precios por los empresarios de la cadena productiva. En concreto se argumenta la importancia de que los agricultores mantengan el control del producto físico mediante esquemas de secamiento y almacenamiento propios del arroz paddy seco. También se discuten algunos de los requisitos y limitaciones actuales para organizar y desarrollar los mercados de físicos y de futuros y derivados para el arroz en la Bolsa Mercantil de Colombia BMC. Esto con el fin de reducir el impacto de la variabilidad de precios sobre el desempeño financiero del negocio arrocero en su fase agrícola, de transformación y distribución.
\end{abstract}

\section{Palabras Clave:}

Arroz, administración de riesgos, riesgo financiero, riesgo de precios

\begin{abstract}
This article documents both the size and trends of rice price fluctuations in Colombia throughout the chain value. It also discusses possibilities for economic agents to implement both conventional and market based price risk management strategies and mechanisms. Specifically, it contends the importance for rice farmers to hold control on the spot market of paddy rice by extending own drying and storage facilities. Main requisites and present constraints to organize the rice cash market as well as the future and derivative market for rice in the Colombian Board of Trade $\mathrm{BMC}$ are presented. The whole discussion aims at reducing the impact of rice price volatility upon the financial performance of the rice business across the supply chain.
\end{abstract}

\section{Key Words:}

Rice, risk management, financial risk, price risk

$1 \quad$ El artículo es una síntesis del estudio para cerrar brechas financieras en arroz adelantado por el Fondo Latino Americano para Arroz Riego FLAR y el Centro Internacional de Agricultura Tropical CIAT, con el apoyo de la Federación Nacional de Arroceros FEDEARROZ y del Fondo para Productos Básicos de las Naciones Unidas CFC. Los autores agradecen a las instituciones mencionadas por facilitar la realización del estudio y la preparación del artículo. Las omisiones y errores, sin embargo, son responsabilidad exclusiva de los autores y no comprometen de manera alguna el pensar y sentir de las instituciones mencionadas.

2 Ph. D. en Economía Agrícola y Docente de la Universidad de Santo Tomás Bucaramanga.

3 Economista MSc y Presidente de Agrobursátil S.A. 


\section{Introducción}

Tweeten (1979) argumenta que uno de los problemas estructurales de la agricultura a nivel mundial es la inestabilidad de los precios del mercado de físicos o de contado ${ }^{4}$ para los productos y recursos. Buena parte de las fluctuaciones en el nivel de los ingresos, retornos y rentabilidad de las inversiones de los empresarios de la agricultura se originan en la variabilidad de los precios. Purcell and Koontz (1999) y Hardaker, et al. (1997) sostienen que las fluctuaciones de los precios exacerban otros riesgos financieros como el de liquidez y de crédito y ponen en peligro la supervivencia de las empresas.

En las regiones tropicales como Colombia, las fluctuaciones de precios e ingresos son especialmente notorias en las cadenas de productos básicos como el arroz. La variabilidad de los precios al agricultor quien vende arroz paddy verde generalmente son mayores que las variaciones del precio del arroz paddy seco y del arroz blanco. En consecuencia, la inestabilidad de precios afecta en mayor grado al cultivador del grano que a los demás empresarios de la cadena.

En las zonas templadas productoras de arroz (ejemplo: Argentina, Estados Unidos, Sur del Brasil, Uruguay) los agricultores son vendedores de arroz paddy seco ya que en su mayoría usan tecnologías de secamiento y almacenamiento en sus fincas 5 y/o contratan estos servicios con proveedores externos sin perder la posesión del producto físico. Esto les permite a los cultivadores, industriales y distribuidores de arroz por igual, mitigar el impacto sobre los ingresos de las fluctuaciones del precio del arroz paddy seco y blanco mediante instrumentos financieros para la administración de este riesgo en los mercados de físicos, futuros y derivados ${ }^{6}$. De este modo, los empresarios no sólo aumentan su poder de negociación del arroz paddy seco y blanco sino que por medio de estos instrumentos pueden:

i. acceder a fuentes de crédito no convencionales para mejorar su liquidez al momento de la cosecha ó durante los procesos industriales pues reduce la necesidad de vender el producto de forma inmediata

ii. transferir ó cubrirse de los riesgos de precios del mercado

iii. contribuir al proceso de descubrimiento de precios del arroz a través del mercado público ó bursátil.

4 Los mercados de físicos (cash ó spot, en inglés) son aquellos donde tiene lugar la transferencia física de un producto. Ya que la entrega de los productos es inmediata y el pago de los mismos se hace de contado ó en efectivo, los mercados de físicos también se les denomina mercados de contado.

5 El proceso de secado consiste en reducir el contenido de humedad del arroz paddy verde del $20-28 \%$ al $12 \%$. El producto del secado es el arroz paddy seco ó arroz cáscara seco.

6 Los mercados de derivados (forwards, futuros, opciones, swaps) existen por dos razones: contribuyen a la determinación del precio por las fuerzas del mercado (oferta y demanda) y son un mecanismo para reducir ó eliminar el riesgo de fluctuaciones de los precios para los compradores y vendedores en los mercados de físicos. 
iv. darle mayor transparencia a las negociaciones entre compradores y vendedores.

v. darle más profundidad y liquidez al mercado bursátil o de capitales.

En contraste, en Colombia al igual que la mayoría de países tropicales productores de arroz, los agentes de la cadena productiva de arroz disponen de escasos mecanismos para el manejo de riesgos de producción, financieros y de mercado. Como lo sostiene Jayne y Myers (2004) en la mayoría de países de menores ingresos el nivel de desarrollo del mercado de físicos es aún imperfecto y los mercados bursátiles no son todavía suficientemente activos en la agricultura bien porque carecen del ambiente normativo y regulatorio requerido y/o por la falta de profundidad y liquidez entre otros factores

La falta de estrategias y mecanismos para la administración de riesgos de mercado y financieros del arroz en Colombia es un factor que restringe la modernización del mercado arrocero e inhibe el mejoramiento de la productividad, eficiencia y desempeño económico del sector.

\section{Marco conceptual}

Anderson et. al. (1977) definen riesgo como la probabilidad de pérdidas financieras para un empresario en agricultura (agricultor, procesador, distribuidor) resultantes de la ocurrencia aleatoria de eventos cuya distribución de frecuencias se conoceo puede estimar con antelación en forma objetiva. Cuando la distribución de los eventos no se puede anticipar con precisión el empresario se enfrenta a una situación de incertidumbre y debe evaluar el nivel de riesgo y sus consecuencias financieras de manera subjetiva

Como se ilustra en el Cuadro 1, los empresarios arroceros enfrentan diferentes tipos de riesgos. Los principales riesgos financieros son: mercados, crédito y liquidez. Los riesgos no financieros incluyen los riesgos operacionales, legales y personales. Los riesgos de producción debido a factores no controlables (clima, plagas y enfermedades) constituyen un tipo de riesgo financiero. Los riesgos de crédito y liquidez son riesgos financieros que emergen cuando el empresario pide prestado dinero y crea una obligación de repagar la deuda. La posibilidad de no encontrar un comprador para el producto o de un vendedor del recurso, insumo ó servicio, genera un riesgo de liquidez. La posibilidad de no poder pagar un crédito, de que el préstamo sea exigido por el prestamista antes de su vencimiento, y las condiciones de acceso al crédito son también aspectos del riesgo financiero.

Anderson y Mapp (1977) documentan que el riesgo de precios es uno de los varios tipos de riesgos de mercado que encaran los agentes de la cadena productiva pero tiene importantes implicaciones sobre los riesgos financieros de producción, liquidez y de crédito. Los riesgos de precios se refieren a la incertidumbre sobre los precios que los empresarios recibirán por los productos que venden o por los precios 
que pagarán por los insumos y servicios que compran. Las variaciones en el precio internacional, la tasa de cambio y tasa de interés son igualmente componentes de los riesgos de precios de mercado. Estos riesgos varían significativamente entre años, ciclos de cosecha, productos y recursos

Los riesgos no financieros incluyen fallas operacionales y legales ó regulatorias. Además de estos, las instituciones son también fuentes de incertidumbre que impactan las actividades en la agricultura. Se generan como consecuencia de su accionar en temas como: aranceles, regulaciones ambientales, niveles de apoyos e incentivos y su acceso. Finalmente, los empresarios enfrentan riesgos personales incluidos factores inciertos como: enfermedades, accidentes y divorcios que afectan la operación de las empresas en la agricultura.

Cuadro 1. Clasificación de los riesgos para los empresarios arroceros en Colombia, sus causas y consecuencias y los mecanismos de cobertura actuales

\begin{tabular}{|c|c|c|c|}
\hline \multicolumn{2}{|c|}{ Riesgos } & Causas y consecuencias & Mecanismos de cobertura actuales \\
\hline \multirow{3}{*}{ 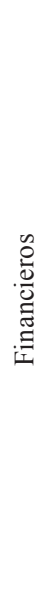 } & 总 & $\begin{array}{l}\text { Clima, enfermedades y plagas } \\
\text { Insolvencia del usuario } \\
\text { Garantías insuficientes } \\
\text { Pérdida parcial o total del producto y de } \\
\text { los ingresos esperados }\end{array}$ & $\begin{array}{l}\text { Seguros de clima } \\
\text { Contratos a plazos (forward) informales } \\
\text { Agricultura por contrato } \\
\text { Fondo Agropecuario de Garantías FAG } \\
\text { Garantías básicas } \\
\text { Control de inversiones }\end{array}$ \\
\hline & $\frac{N}{\stackrel{n}{\Xi}} \cdot \frac{\pi}{3}$ & $\begin{array}{l}\text { Incapacidad para hacer efectivos los } \\
\text { activos y obligaciones } \\
\text { Pérdidas financieras y de producto }\end{array}$ & $\begin{array}{l}\text { Contratos a plazos (forward) informales } \\
\text { Certificados de Depósito de mercancías } \\
\text { CDM } \\
\text { Operaciones Repo sobre CDM }\end{array}$ \\
\hline & 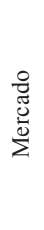 & $\begin{array}{l}\text { Tendencias de precios de productos y } \\
\text { recursos } \\
\text { Variaciones cíclicas y estacionales de } \\
\text { precios de productos y recursos } \\
\text { Fallas para encontrar comprador ó } \\
\text { vendedor } \\
\text { Pérdidas financieras }\end{array}$ & $\begin{array}{l}\text { Contratos a plazos ( forward) informales } \\
\text { Fondo Agropecuario de Garantías FAG } \\
\text { Agricultura por contrato } \\
\text { Garantías básicas }\end{array}$ \\
\hline \multirow{2}{*}{ 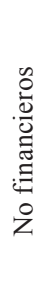 } & 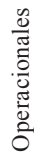 & $\begin{array}{l}\text { Fallas en sistemas y controles, procesos y } \\
\text { procedimientos } \\
\text { Pérdidas financieras y de producto }\end{array}$ & $\begin{array}{l}\text { Planificación y control técnico y } \\
\text { financiero }\end{array}$ \\
\hline & 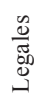 & $\begin{array}{l}\text { Fallas en los términos y condiciones de los } \\
\text { contratos }\end{array}$ & $\begin{array}{l}\text { Listas de chequeo } \\
\text { Contratos estandarizados } \\
\text { Formas estandarizadas }\end{array}$ \\
\hline
\end{tabular}

Fuente: Ramírez, et al. (2008) 
Según Boehlje y Trede(1977) y Barry y Baker (1984) la estrategia de administración de riesgos en agricultura para todo empresario con aversión al riesgo se inicia con la formulación del plan de producción y del plan de mercadeo. Estos planes conducen a la identificación y selección de la(s) actividad(es) productiva(s) que le(s) permite(n) alcanzar el nivel esperado de ganancias dentro de un nivel de riesgo aceptable de acuerdo con su grado de aversión al riesgo y su capacidad para tolerar riesgos.

Fleisher (1990) y Hardaker et al. (1997) argumentan que, el diseño de estos planes debe anticipar las estrategias de manejo de riesgos en tres temas relacionados:

- Reducción de los riesgos dentro de la empresa arrocera (ejemplo: diversificación de actividades productivas, integración vertical, inversión en o alquiler de infraestructura básica de procesos como el secamiento y almacenamiento en finca, trilla, empaque, transporte y compra de seguros)

- Fortalecimiento de la capacidad para tolerar riesgos (ejemplo: uso de reservas en efectivo, estabilización de los flujos de caja) y,

- Transferencia del riesgo fuera de la empresa mediante mecanismos como: proyectos integrados de producción y mercadeo, agricultura por contrato, contratos de producción y/o mercadeo, contratos a plazos oforward, contratos de futuros y opciones entre otros.

En un escenario estándar de desarrollo del mercado de físicos y bursátil el manejo de riesgos de precios en el arroz involucra tres componentes: a) el análisis tanto del mercado de físicos como del mercado bursátil para identificar los tipos, fuentes y persistencia de las variaciones de precios y los instrumentos o alternativas disponibles para su manejo; b) el análisis fundamental y técnico para cuantificar la magnitud de los riesgos, y establecer los límites de tolerancia al riesgo para su control, y c) la identificación de los mecanismos de mitigación del riesgo a través de: la disminución a la exposición (ejemplo, secamiento y almacenamiento en fincas) y/o la transferencia del riesgo mediante el uso de coberturas con los mercados de futuros, derivados y seguros

Según Ramírez et al. (2008) la administración de riesgos de los precios del arroz es un tema de la mayor relevancia para el sector debido a:

a. el entorno de política de apertura comercial en donde los precios de los mercados internacionales se han convertido en los precios de referencia para la formación de los precios domésticos.

b. la necesidad de mejorar la eficiencia y competitividad de la producción y mercadeo del arroz a fin de garantizar el ahorro de divisas por las importaciones actuales y en el futuro inmediato la ganancia de más divisas por exportaciones de arroz para el desarrollo de la economía. 
c. finalmente, el contexto de cambio climático donde la oferta nacional es especialmente afectada por los fenómenos climáticos que hacen más variable la producción y los precios.

Colombia es un importador ocasional de arroz paddy seco y blanco de Ecuador, Venezuela y Estados Unidos. Históricamente el volumen de importaciones registradas y de contrabando es inferior al $12 \%$ del consumo interno. Los precios externos además de que distorsionan el nivel de precios internos del arroz, aumentan la volatilidad. La mayor variabilidad de precios se atenúa por medio de mecanismos como: las bandas (franjas) de precios con aranceles variables; el esquema de administración de contingentes de importación ligado a la absorción de la producción nacional; y el incentivo al almacenamiento.

En el estudio de Ramírez et al. (2007) se encontró que, la principal fuente estructural de fluctuaciones de los precios internos del arroz paddy verde y seco era la estacionalidad de la producción interna explicada en su mayor parte por la inestabilidad del área sembrada a través del año. Los excedentes de arroz paddy verde en el mercado se presentan en el segundo semestre del año, mientras que se registra un déficit de arroz paddy verde, seco y blanco en el primer semestre. Para aliviar el efecto sobre la variabilidad de los precios se cuenta con el incentivo al almacenamiento.

No obstante, la existencia de los mecanismos mencionados anteriormente de estabilización de precios no garantiza per se menores fluctuaciones de precios principalmente para los agricultores productores de arroz paddy verde ya que, los beneficios directos de la estabilización a través de los instrumentos mencionados, los capturan en mayor grado los industriales y distribuidores de la cadena productiva.

Martínez et al. (2007) documenta que, con la iniciación de operaciones de la Bolsa Nacional Agropecuaria BAN desde 1979, el país ha acondicionado la estructura y normatividad para organizar, desarrollar y mantener en funcionamiento un mercado público de bienes y productos agropecuarios, agroindustriales y de otros productos básicos sin la presencia física de los mismos, así como de servicios, documentos de tradición o representativos de mercancías, títulos, valores, derechos, derivados y contratos negociables

En virtud de la Ley 964 del 2005 en estos mercados públicos se pueden celebrar operaciones de entrega inmediata; operaciones sobre físicos disponibles; operaciones a término, forward, de futuros, y opciones sobre bienes y productos físicos, documentos, títulos, valores, derechos, derivados, contratos con subyacente agropecuario, agroindustrial o de otros productos básicos.

En el 2010, la antigua BNA se transformó en la BMC a fin de ampliar el mercado público a futuros y derivados de otros productos básicos como: café, carbón, clima, dólar, electricidad, gas, oro y petróleo, entre otros. Además de su extensión a otras 
operaciones con instrumentos financieros tales como: repos sobre certificados de depósito de mercancías sin interposición de contraparte, facturas cambiarias, contratos de exportación, venta definitiva de facturas, titularizaciones, emisiones de $\mathrm{CO}_{2}$, entre otros.

En este escenario, el estudio, diseño e implementación de alternativas para la administración de riesgos de precios de productos de la agricultura mediante instrumentos basados en los mercados públicos como el de la BMC son múltiples y se constituyen en un desafío para los académicos, docentes e investigadores de las áreas económicas, administrativas y financieras.

\section{Marco Analítico}

Según Purcell (1979) en el caso de productos de la agricultura no perecederos o almacenables como el arroz, la administración de riesgos de mercado y financieros generalmente comprende el uso de dos estrategias complementarias: la primera tiene que ver con el control del producto físico a nivel de las empresas (agricultor, industrial, distribuidor). La segunda, con el acceso a instrumentos de cobertura de riesgos de precios y financieros en los mercados públicos ó bursátiles. El énfasis en la administración de riesgos se centra en la producción, mercadeo y financiamiento del arroz paddy seco (agricultor), arroz paddy seco y blanco (procesador-transformador) y arroz blanco (distribuidor).

A nivel de la empresa arrocera el instrumento básico para la administración moderna de riesgos financieros (de producción, mercado, crédito y liquidez) lo constituye el arroz mismo como subyacente principal de contratos de compra - venta sobre disponibles, forward y futuros. Así, la primera estrategia consiste en mantener el control sobre el producto físico en la forma de arroz paddy seco ó blanco, antes de salir al mercado. Para ello, los empresarios necesitan desarrollar inversiones en el secamiento del arroz paddy verde y en el procesamiento y almacenamiento del arroz paddy seco y/o blanco. En caso contrario, los empresarios arroceros deben contratar estos servicios de un proveedor pero sin la transferencia del dominio sobre el arroz paddy seco o el arroz blanco.

El control sobre el producto físico le otorga al empresario un mayor poder de negociación y la posibilidad de acceder a financiamiento de fuentes no convencionales mientras que simultáneamente realiza la cobertura del riesgo de precios en el mercado bursátil. Es decir, el control del producto físico por el agricultor, procesadortransformador y distribuidor de arroz es una condición necesaria para el adecuado manejo de los riesgos de mercado y financieros.

La condición suficiente es que exista un mercado público activo de futuros y derivados en el cual se pueda adelantar la segunda estrategia que consiste en hacer 
la transferencia o cobertura del riesgo mediante el uso del producto físico como subyacente de contratos de disponibles y forward en operaciones de físicos y de futuros en operaciones financieras. El contrato de futuros da lugar a un instrumento financiero derivado ó activo financiero conocido como opciones cuyo valor depende del valor del subyacente, en este caso, del contrato de futuros cuyo valor, a su vez, es función del arroz como subyacente.

Purcell y Koontz (1999) identifican los derivados u opciones como instrumentos financieros con fines de cobertura o inversión (especulación y/o arbitraje). Estos autores argumentan que su finalidad es reducir el riesgo que resulta de movimientos inesperados en el precio del activo subyacente mediante la distribución del riesgo entre los participantes que quieren disminuirlo (empresarios) y aquellos que desean asumirlo (inversionistas ó especuladores y arbitradores).

Lutgen y Todd (1997) sostienen que la existencia de un mercado de contratos de futuros y derivados se debe a que las empresas o coberturistas (hedgers en inglés) desean asegurar el precio futuro del activo subyacente así como su disponibilidad en el futuro mediante el contrato de futuros, mientras que, otras empresas o individuos inversionistas ó especuladores (speculators en inglés) esperan obtener una ganancia que resulta de los cambios esperados en el valor ó precio del activo financiero subyacente ó contrato de futuros. Por tanto, mientras que hay empresas ó individuos que desean cubrir el riesgo hay otras que los asumen.

El Cuadro 2 ilustra los principales requisitos que los mercados públicos de futuros y derivados necesitan satisfacer para que los empresarios arroceros puedan hacer la cobertura de riesgos de precios en estos mercados

Cuadro 2. Condiciones mínimas requeridas para el desarrollo de un mercado de futuros y derivados local y global

\begin{tabular}{|l|c|c|c|}
\hline \multirow{2}{*}{\multicolumn{1}{c|}{ Condición }} & \multirow{2}{*}{$\begin{array}{c}\text { Mercado } \\
\text { OTC1 } \\
\end{array}$} & $\begin{array}{c}\text { Contratos } \\
\text { Forward }\end{array}$ & \multicolumn{2}{c|}{$\begin{array}{c}\text { Mercado Abierto } \\
\text { de Derivados }\end{array}$} \\
\cline { 3 - 5 } & Local & Global \\
\hline Volatilidad de precios & $\mathrm{X}$ & $\mathrm{X}$ & $\mathrm{X}$ \\
\hline Marco regulatorio bursátil adecuado & $\mathrm{X}$ & $\mathrm{X}$ & - \\
\hline Cámara de compensación & - & $\mathrm{X}$ & - \\
\hline Infraestructura tecnológica & - & $\mathrm{X}$ & - \\
\hline Estabilidad macroeconómica & $\mathrm{X}$ & $\mathrm{X}$ & $\mathrm{X}$ \\
\hline Mercado de físicos organizado & $\mathrm{X}$ & $\mathrm{X}$ & $\mathrm{X}$ \\
\hline
\end{tabular}




\begin{tabular}{|l|c|c|c|}
\hline $\begin{array}{l}\text { Profundidad y liquidez del mercado de físicos y } \\
\text { bursátil }\end{array}$ & $\mathrm{X}$ & $\mathrm{X}$ & - \\
\hline $\begin{array}{l}\text { Alta correlación de precios (local versus } \\
\text { internacional) }\end{array}$ & - & - & $\mathrm{X}$ \\
\hline
\end{tabular}

Fuente: Ramírez, et al. (2008).

Notas: X: condición requerida; - : condición no requerida.

1/ Las operaciones bursátiles OTC (Over the counter) son aquellas que se realizan por fuera del mercado abierto ó mercado de rueda

En base a estas consideraciones el análisis se enfoca a: a) determinar el nivel de riesgo de precios que enfrentan los empresarios; b) confirmar el grado en el cual los agricultores mantienen la posesión física del arroz mediante actividades de secamiento y almacenamiento; c) establecer en qué medida y con qué objeto los empresarios usan el mercado bursátil actual; y d) identificar en qué medida las condiciones enumeradas en el Cuadro 2 anterior se satisfacen para el desarrollo de un mercado bursátil con capacidad de cubrir riesgos de precios. Así mismo, a identificar instrumentos para hacer coberturas de riesgos de precios y financieros dado el ambiente regulatorio y organizacional del mercado bursátil actual.

\section{Resultados y análisis}

\subsection{Magnitud de las fluctuaciones de precios}

El nivel de variabilidad de los precios en el mercado de contado o de físicos del arroz representa el nivel de riesgo inherente que se pretende cubrir. Los mercados de bienes agrícolas para funcionar eficientemente necesitan de un nivel "natural" de volatilidad de precios que estimule las transacciones y los ajustes de la oferta y demanda pero sin que ésta sea mayor de un determinado nivel. Los estudios económicos realizados por Anderson, et al., (1977) sobre el nivel de variabilidad a partir del cual es rentable tomar medidas de mitigación y cobertura de riesgos de precios en la agricultura definen un nivel del 3\% ó más, medido por el coeficiente de variación $\mathrm{CV}$.

Los datos usados para medir la variabilidad de precios del arroz paddy del siguiente análisis corresponden a series de tiempo (anuales y mensuales) sobre la evolución de los precios recibidos por los agricultores en el período 1990 - 2006 reportados por la Federación Nacional de Cultivadores de Arroz FEDEARROZ. El análisis de precios para el agricultor, industrial y el consumidor se extendió a la tasa de cambio, la tasa de interés y el precio internacional del arroz (Bangkok y Estados 
Unidos) variables que inciden en los riesgos de mercado y financieros que enfrentan los productores y distribuidores de arroz.

Los precios nominales del arroz, tasa de cambio y tasa de interés de cada año se deflactaron a precios reales mediante el Índice de Precios al Productor IPP del Banco de la República. Los precios internacionales expresados en dólares se deflactaron por el Índice de Precios al Consumidor IPC del Departamento del Trabajo de los Estados Unidos. Los precios reales se ajustaron mediante modelos de regresión lineal para observar los cambios en su nivel, tendencias y patrones de variación en el tiempo.

Como indicador del riesgo de las variaciones de precios en el largo plazo se usó el CV de la serie anual de precios. Este estadístico permite hacer comparaciones de la magnitud de las fluctuaciones de precios en el tiempo, entre productos, y/o entre regiones. La variabilidad de precios a través de los años influencia la expansión de las empresas, las decisiones de inversión en activos de capital y tiene una responsabilidad directa en la supervivencia de las empresas. Además, la variabilidad entre años refleja el ambiente de riesgo de una actividad frente a otras actividades productivas.

El CV de las series mensuales de precios, a su vez, se usó para medir el grado de volatilidad de los precios del arroz dentro de cada año el cual afecta las decisiones sobre la combinación y nivel de las actividades de las empresas así como las estrategias de manejo del riesgo y de mercadeo. Para medir la importancia de las variaciones estacionales en la volatilidad de precios del arroz se calculó el índice de estacionalidad con el método de promedios móviles centrados a 12 meses usado por Purcell (1979).

Según los datos del estudio tanto los agricultores como los industriales y consumidores de arroz enfrentan riesgos de precios significativamente superiores al 3\% y ameritan medidas para mitigar su impacto sobre los ingresos y rentabilidad de las inversiones en la producción de arroz paddy verde, el procesamiento del arroz paddy seco y la distribución y consumo del arroz blanco (Cuadro 4)

Cuadro 4: Indicadores de la magnitud de las variaciones de los precios reales del arroz 1992-2006

\begin{tabular}{|l|c|c|c|}
\hline \multirow{2}{*}{ Indicadores } & \multirow{2}{*}{$\begin{array}{c}\text { Arroz paddy verde } \\
\text { agricultor }\end{array}$} & \multicolumn{2}{c|}{ Arroz blanco de primera } \\
\cline { 3 - 4 } & 386.7 & 781.9 & 1036.5 \\
\hline Promedio $(000$ \$/ton $)$ & $321.5-499.6$ & $648.6-1024.2$ & $936.1-1164.7$ \\
\hline $\begin{array}{l}\text { Rango de variación } \\
(000 \text { \$/ton })\end{array}$ & 36.0 & 84.7 & 56.6 \\
\hline $\begin{array}{l}\text { Desviación estándar } \\
(000 \text { \$/ton })\end{array}$ & \multicolumn{2}{|l}{} \\
\hline
\end{tabular}




\begin{tabular}{|l|c|c|c|}
\hline Coeficiente de variación (\%) & 9.3 & 10.8 & 5.5 \\
\hline Índice de estacionalidad (\%) & $\begin{array}{c}103.1 \text { (Mayo) } \\
\text { Máximo }\end{array}$ & $\begin{array}{c}103.5 \text { (Mayo) } \\
96.4 \text { (Oct.) }\end{array}$ & $\begin{array}{c}101.0 \text { (Marzo) } \\
99.1 \text { (Nov.) }\end{array}$ \\
\hline
\end{tabular}

Fuente: Ramírez et al. (2007)

Las variaciones interanuales de precios confirman que la actividad arrocera es una inversión riesgosa y que la carencia de instrumentos para su manejo puede: a) conducir a la desestabilización del ingreso de los productores y distribuidores; b) representar un desestímulo a la inversión y al uso óptimo de los recursos; y c) promover la transferencia de recursos desde el sector a otras actividades económicas.

La estacionalidad de las áreas sembradas y de la producción resulta en un comportamiento estacional de los precios al productor. El índice de estacionalidad de éstos crece en el primer semestre, alcanza su máximo nivel en Mayo, 103.1, para declinar hasta Septiembre cuando llega a su nivel más bajo, 96.7 (Gráfica 1)

Gráfica 1. Variaciones estacionales de los precios del arroz paddy verde a nivel de agricultor

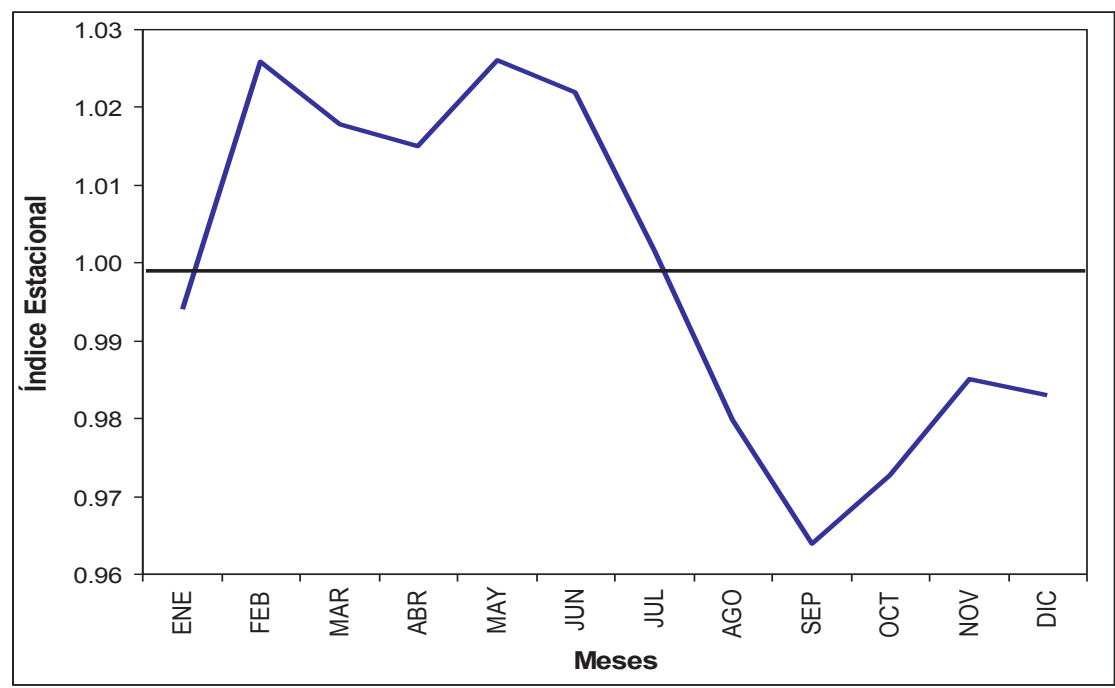

Fuente: Ramírez et al. (2007) 
Las variaciones estacionales de los precios mensuales del arroz son una fuente de volatilidad adicional que conduce a transferencias de ingreso significativas entre los agentes de la cadena. Por ejemplo, los agricultores con altos costos variables y / altos pasivos a la vista, confrontan riesgos de mercado y de liquidez en períodos de exceso de cosechas debido a la caída inesperada de los precios. Como consecuencia, generalmente no pueden pagar a los acreedores (bancos y proveedores de insumos). En épocas de escasez de arroz paddy verde, los proveedores de insumos, bancos y procesadores usualmente registran incrementos en los costos lo cual se refleja en mayores precios del grano y los insumos para los agricultores y el consumidor. De hecho la estacionalidad de los precios del arroz paddy seco y blanco está altamente correlacionada con el precio del arroz paddy verde (coeficiente de correlación parcial de 0.92 y 0.59 respectivamente)

Según los índices de estacionalidad calculados el márgen máximo de variación estacional de los precios del arroz paddy verde es hasta de un 6\%. En la medida que las fechas de siembra del arroz se continúen concentrando para aprovechar los picos de radiación solar y aumentar la productividad, se puede esperar que la estacionalidad actual de precios se incremente. La rentabilidad de las inversiones en secamiento y almacenamiento del arroz a nivel del agricultor y el industrial se aumenta con el incremento en el índice de estacionalidad. Por lo tanto, la conveniencia financiera que los agricultores cuenten con esquemas de secamiento y almacenamiento son evidentes.

Como se observa en el Cuadro 4 anterior, las fluctuaciones ínteranuales de los precios reales al consumidor presentan la menor variabilidad. Comparada con el CV del precio al agricultor y al industrial, la variabilidad del precio al consumidor es cerca de la mitad. Las importaciones legales e ilegales del producto en épocas de escasez y el flujo de arroz entre zonas con excedentes y zonas con faltantes de arroz paddy seco ó blanco, son mecanismos que en Colombia ayudan a la estabilización de los precios pagados por el consumidor y explican su menor variación.

Mediante reuniones focales con agricultores y expertos calificados Ramírez et al. (2007) confirmaron que: a) los cultivadores de arroz no disponen de facilidades de secamiento y almacenamiento propias ó contratadas; b) como consecuencia, tienen muy bajo poder de negociación como vendedores de arroz paddy verde; y c) pierden el control sobre el producto físico una vez entregan el arroz al industrial para su procesamiento. En este escenario, sólo si los cultivadores pueden producir arroz paddy seco y mantener la posesión física del arroz podrán tener la posibilidad de administrar los actuales riesgos de mercado y financieros que enfrentan.

Los riesgos de precios y de iliquidez por falta de un comprador para los cultivadores en situaciones de excedentes del grano se atenúan indirectamente con el incentivo al almacenamiento. El incentivo fue creado por la Ley 101/1993. Sin embargo, en la actualidad se paga sólo a los procesadores de arroz en cáscara ( $p a d d y$ ) húmedo 
(verde) con capacidad de secamiento y almacenamiento, de acuerdo a la compra del producto a un precio de referencia establecido por el Ministerio de Agricultura y Desarrollo Rural MADR.

Además del incentivo al almacenamiento, los industriales procesadores y transformadores del arroz quienes producen y almacenan arroz paddy seco y blanco actualmente se benefician directamente de: a) el mecanismo para mitigar el impacto del riesgo de iliquidez a través de las operaciones REPO sobre Certificados de Depósito de Mercancías CDM representativos de arroz paddy seco y arroz blanco; y b) el mecanismo de subastas públicas para la administración de contingentes de importación de arroz en cáscara seco y arroz blanco creado por el Decreto 430 del 2004.

El margen bruto de mercadeo definido como el diferencial de precio al entrar y al salir el arroz de un determinado segmento de la cadena, muestra que el margen agricultor - industrial es el de mayor magnitud y el de menor variabilidad (Cuadro 5). Este margen representa el $62 \%$ del margen total del mercado agricultor - consumidor y el CV del $13.7 \%$ es casi la mitad del estimado para el margen industrial - consumidor (26\%). Lo anterior sugiere que en términos de fluctuaciones de precios del arroz, el segmento industrial es el que enfrenta el menor riesgo por su posición negociadora dominante y que su rentabilidad depende básicamente de su eficiencia operativa.

Cuadro 5: Indicadores de la magnitud de las variaciones de los márgenes de mercado del arroz 1992-2006

\begin{tabular}{|c|c|c|c|c|}
\hline \multirow{2}{*}{\begin{tabular}{c} 
Margen mercado \\
\cline { 2 - 5 }
\end{tabular}} & Promedio & $\begin{array}{c}\text { Desviación } \\
\text { estándar }\end{array}$ & $\begin{array}{c}\text { Rango de } \\
\text { variación }\end{array}$ & $\begin{array}{c}\text { Coeficiente } \\
\text { Variación }\end{array}$ \\
\cline { 2 - 5 } & \multicolumn{3}{|c|}{$(000 \$ /$ ton $)$} \\
\hline Industrial - Consumidor & 246.1 & 63.9 & $50.0-363.0$ & 26.0 \\
\hline Agricultor -Industrial & 400.8 & 55.0 & $327.1-531.1$ & 13.7 \\
\hline Agricultor - Consumidor & 646.9 & 41.2 & $563.1-733.1$ & 6.4 \\
\hline
\end{tabular}

Fuente: Ramírez et al. (2007)

La variabilidad mensual de la tasa de cambio (11.1\%) es muy similar a la estimada para los precios al agricultor e industrial de arroz (Cuadro 6). En la medida en que el mercado nacional se conecta con los mercados internacionales, bien sea en calidad de importador de arroz ó de insumos o como eventual exportador de arroz, las oscilaciones de la tasa de cambio cobran mayor relevancia como un factor adicional de riesgos de mercado en el sector arrocero colombiano. La implementación de mercados de futuros y derivados con coberturas de precios y de tasas de cambio, 
podría ser una alternativa novedosa y eficaz para reducir riesgos y garantizar un nivel de financiación adecuado.

La tasa de interés o precio del capital presenta un amplio espectro de volatilidad que se manifiesta en un elevado CV del 56.7\% (Cuadro 6).

Cuadro 6. Indicadores de las variaciones de los precios reales de otras variables críticas en la cadena del arroz

\begin{tabular}{|c|c|c|c|c|}
\hline \multirow[b]{2}{*}{ Indicadores } & \multirow{2}{*}{$\begin{array}{l}\text { Tasa cambio } \\
\text { \$Col/1 \$US } \\
1992-20061\end{array}$} & \multirow{2}{*}{$\begin{array}{c}\text { Tasa interés } \\
\% \\
1990-20062\end{array}$} & \multicolumn{2}{|c|}{ Precio externo (US\$/tm) } \\
\hline & & & $\begin{array}{c}\text { USA } \\
1989-20063\end{array}$ & $\begin{array}{c}\text { Tailandia } \\
1985-20064\end{array}$ \\
\hline Promedio & 1670.9 & 6.0 & 160.2 & 263.9 \\
\hline Rango variación & $1336-2067$ & $0.3-12.0$ & $84.0-227.1$ & $169.8-393.3$ \\
\hline Desviación típica & 185.8 & 3.4 & 38.5 & 55.7 \\
\hline Coeficiente variación (\%) & 11.1 & 56.7 & 24.0 & 21.1 \\
\hline $\begin{array}{c}\text { Índice estacionalidad (\%) } \\
\text { Máximo } \\
\text { Mínimo }\end{array}$ & $\begin{array}{l}102.3 \\
\text { Octubre } \\
98.0 \text { Abril }\end{array}$ & $\begin{array}{c}108.9 \\
\text { Diciembre } \\
78.3 \text { Enero }\end{array}$ & $\begin{aligned} 102.3 & \text { Enero } \\
96.2 & \text { Sep. }\end{aligned}$ & $\begin{array}{l}105.3 \\
\text { Febrero } \\
\text { 97.6 Dic. }\end{array}$ \\
\hline
\end{tabular}

Fuente: Ramírez et. al. (2007)

Notas. 1/ Serie deflactada por el IPP7 1999=100. 2/ Tasa promedio mensual de los CDT a 90 días. Tasa real $=($ tasa nominal - tasa de inflación $) /(1+$ tasa de inflación $) ; 3 /$ precio al agricultor grano largo 5\% partido; 4/ FOB Bangkok, Grado B.

Estos resultados resaltan la importancia de que al interior de la cadena se diseñen mecanismos de financiación de fuentes no convencionales para los agricultores que estén ligadas a instrumentos bursátiles como el REPO sobre CDM. Como lo sostiene Miller, et al. (1993) estos instrumentos garantizan una fuente de financiación más ágil y oportuna, mayor estabilidad en el costo del financiamiento y reducción del riesgo de pérdidas por insolvencia y recuperación de cartera, más aún cuando el crédito de fuentes informales de financiamiento del cultivo del arroz continúa siendo la principal forma de financiación de los agricultores y se mantiene alrededor del 80\% desde 1999 (Cuadro 7). De hecho, la participación de las alternativas de crédito institucional formal se ha reducido drásticamente desde el nivel del 43.7\% en 1988 al $13.2 \%$ en el 2006 que sugiere que los agricultores han perdido capacidad de crédito ó acceso al mercado financiero formal.

A pesar de los incentivos de los préstamos formales para la competitividad y sectoriales (incentivo a la capitalización rural ICR, agro ingreso seguro AIS, FINAGRO, seguro agropecuario y el Fondo Agropecuario de Garantías FAG), los

$7 \quad$ IPP $=$ Índice de Precios al Productor según el Banco de la República 
cultivadores de arroz reportan dificultades de acceso a la financiación formal. De acuerdo con las sesiones de grupo realizadas, estas dificultades están tipificadas en: a) el alto riesgo de iliquidez de la actividad percibida por los bancos; b) los trámites y papeleos para la obtención del crédito bancario; c) las limitaciones financieras (patrimonio, liquidez, capacidad de endeudamiento de los agricultores), y d) los reportes del comportamiento crediticio en las centrales de riesgo. Las fuentes informales ofrecen a su vez: a) más agilidad y oportunidad en la asignación de los cupos de crédito que reducen los costos de las transacciones; b) facilitan las relaciones comerciales permanentes prestamista-prestatario y; c) son menos exigentes en la constitución de garantías ya que los compromisos de la obligación se basan más en la producción del arroz paddy verde que en el patrimonio neto del cultivador.

Cuadro 7: Composición del crédito para el cultivo de arroz mecanizado según fuentes 1988-2006

\begin{tabular}{|c|c|c|c|c|c|}
\hline Año & Indicador & Informal & Formal & Sin Crédito & Total \\
\hline \multirow{2}{*}{ 1988A } & Área (has) & 236,602 & 202,547 & 24,537 & 463,686 \\
\cline { 2 - 6 } & $\%$ & 51.0 & 43.7 & 5.3 & 100.0 \\
\hline \multirow{2}{*}{ 1999A } & Área (has) & 288,963 & 57,609 & 18,542 & 365,114 \\
\cline { 2 - 6 } & $\%$ & 79.1 & 15.8 & 5.1 & 100.0 \\
\hline \multirow{2}{*}{ 2006A } & Área (has) & 202,468 & 33,142 & 15,707 & 251,317 \\
\cline { 2 - 6 } & $\%$ & 80.6 & 13.2 & 6.2 & 100.0 \\
\hline
\end{tabular}

Fuente: FINAGRO, FEDEARROZ (Censos de 1988, 2000 y 2007)

Los precios internacionales de referencia presentan una volatilidad sustancialmente mayor que la de los precios internos (21 al 24\%). Con el fin de examinar ex post el impacto de la variabilidad del precio internacional sobre el precio doméstico del arroz, se hizo un análisis de descomposición de la varianza del precio interno del arroz paddy seco (Cuadro 8).

Cuadro 8. Descomposición de la varianza del precio de arroz paddy seco equivalente recibido por el agricultor 1990-2006.

\begin{tabular}{|c|c|c|c|c|}
\hline \multicolumn{5}{|c|}{ Modelo de regresión estimado y varianzas } \\
\hline Coeficientes & Valores de $\mathrm{t}$ & Varianzas & Valor & $\%$ \\
\hline$\partial=-603,411$ & 1.58 & Precio internacional $(\mathrm{PI})$ & 2,657 & 7.4 \\
\hline$\beta=1,021.1$ & 1.72 & Producción interna $(\mathrm{PR})$ & 28,803 & 81.1 \\
\hline$\gamma=0.381$ & 3.86 & Residuo $(\mu)$ & 15,677 & 44.0 \\
\hline
\end{tabular}




\begin{tabular}{|c|c|c|c|c|}
\hline $\mathrm{R} 2=0.416$ & - & Covarianza (PI - PR) & $-11,581$ & -32.5 \\
\hline Valor de $\mathrm{F}=9.81$ & - & Precio paddy seco (PA) & 35,635 & 100 \\
\hline \multirow{5}{*}{} & CV precio externo (PI) & \multicolumn{2}{|c|}{18.7} \\
\cline { 2 - 4 } & CV Precio interno (PA) & \multicolumn{2}{|c|}{24.8} \\
\cline { 2 - 4 } & Relación CV PA/ CV PI & \multicolumn{2}{|c|}{1.33} \\
\cline { 2 - 4 } & Correlación (PA - PI) & \multicolumn{2}{|c|}{-0.37} \\
\hline
\end{tabular}

Fuente: Ramírez et. al. (2007)

Según este análisis la variación total del precio al industrial era explicable en $7.4 \%$ por la variación del precio del arroz importado, $81.1 \%$ por las fluctuaciones en producción, $-32.5 \%$ por la covarianza entre el precio internacional y el nivel de producción interna y, $44.0 \%$ por factores aleatorios. Es decir, las fluctuaciones del precio interno se originan más que todo en las variaciones del volumen de producción y por factores internos del mercado del arroz paddy, no determinados.

Las medidas de protección en frontera (bandas de precios y arancel) invierten el efecto de la variabilidad en el precio de importación sobre la volatilidad interna como lo indica el signo negativo de la covarianza entre el precio externo y la producción doméstica. Si la variabilidad del precio de importación aumenta (disminuye) el efecto de la franja de precios es reducir (aumentar) la variabilidad del precio doméstico y, por tanto, de la producción. Esto también lo comprueba la correlación negativa que existe entre el nivel de los precios internacionales del arroz y el precio interno estimada en 37\% para el período 1991-2006.

El desarrollo e implementación de esquemas de mercados de futuros y derivados es una alternativa apropiada para minimizar los riesgos inducidos por la variabilidad de los precios internacionales de arroz en ausencia del sistema de bandas de precios ó en un eventual proceso de desgravación arancelaria, si el grado de inserción futuro de la agroindustria del arroz en el mercado internacional se aumenta a través de importaciones o de exportaciones del grano

\subsection{Marco legal y regulatorio del mercado bursátil}

La implementación y desarrollo de un mercado de futuros y derivados, requiere un marco regulatorio ajustado a los estándares internacionales (Basilea I y $\mathrm{II}^{8} \mathrm{e}$

8 El Comité de Basilea, constituye un foro de debate para la resolución de problemas específicos de supervisión. Coordina la distribución de las competencias supervisoras entre las autoridades nacionales, a fin de garantizar una supervisión eficaz de las actividades financieras, bursátiles y aseguradoras, y en el futuro las normas de supervisión transfronteriza que se han convertido en un referente en todo el mundo. 
$\mathrm{IOSCO}^{9}$ ) y fundamentado en instituciones con funciones de inspección, vigilancia y control sobre las personas que realizan actividades bursátiles, financieras y cualquier otra relacionada con el manejo, aprovechamiento o inversión de recursos captados del público. Además, requiere disponer de la base jurídica apropiada para proyectar la actividad bursátil conforme a los requerimientos del mercado (Martínez, et al., 2007).

Un hecho relevante en el ambiente regulatorio colombiano es la Ley del Mercado Público de Valores (Ley 964/2005) que introdujo cambios fundamentales al funcionamiento del mercado de valores, incluidas las Bolsas de bienes, productos agropecuarios, agroindustriales o de otros commodities y sus miembros ${ }^{10}$ las cuales fueron reconocidas como organismos y agentes del mercado de valores. Así, estas instituciones y personas hacen parte del ámbito de la inspección, vigilancia y control de la Superintendencia Financiera, y cuentan con autorización para adelantar actividades de intermediación de valores en los mercados de productos básicos, agroindustriales, títulos, valores y derivados. A su vez, el decreto 1511/2006 reglamentario de la ley, estableció las normas aplicables a las bolsas de productos, sus miembros, sistemas y organismos de compensación y liquidación y organismos de autorregulación sustentadas en los lineamientos de Basilea I, II e IOSCO.

Según el estudio de Martínez et al. (2007) la Bolsa Mercantil de Colombia BMC, la Cámara de Riesgo Central de Contraparte CRC de la BMC y sus Miembros cuentan con la infraestructura adecuada para la operación de los mercados de físicos e instrumentos financieros y han adecuado sus organizaciones a los nuevos estándares establecidos por la ley, de tal forma que disponen de los medios y mecanismos para el desarrollo de los mercados de futuros y derivados financieros.

\subsection{Sistema de información del mercado bursátil}

Los sistemas de información de la BMC están estratégicamente soportados en programas de conectividad y tecnologías de información y comunicación $\mathrm{TIC}^{11}$, que permiten implementar estrategias para: crear, adaptar, promover y masificar la información del mercado bursátil y desarrollar una economía digital, entendida como toda la información en sus diferentes formatos que fluye por redes de telecomunicaciones para crear comunidad bursátil. Los sistemas de información y evaluación de Mercados SIEM, implementados por la BMC, se han constituido

9 IOSCO, International Organization of Securities Commission.

10 Título Séptimo, artículo 71, Parágrafos 1,2 y3.

11 Las Tecnologías de la Información y las Comunicaciones, TIC, son el conjunto de instrumentos, herramientas y medios de comunicación como la telefonía, los computadores, el correo electrónico y la red de Internet que permiten la comunicación entre las personas y las organizaciones. El aprovechamiento de estas tecnologías permite el acceso sistemático a la información que conlleva al incremento de la productividad y a la eficiencia y transparencia de los mercados 
en una de las fortalezas del foro bursátil, incluido los sistemas de evaluación de mercados

\subsection{Estabilidad macroeconómica}

Para el desarrollo de un mercado de futuros y derivados financieros, es fundamental que persistan condiciones de estabilidad en el ámbito macroeconómico, que permitan la formación de expectativas ciertas, confiables y favorables sobre los precios de los productos, recursos y servicios y la rentabilidad esperada de los contratos de futuros. La política monetaria, comercial y fiscal requiere ser favorable para la producción, comercio y consumo de los productos. En caso contrario, la política sectorial debe disponer de incentivos y mecanismos compensatorios que atenúen los efectos e impactos negativos de la política macroeconómica sobre los productos.

A partir de la crisis económica de 1999 y hasta el 2007 la economía colombiana creció en forma más estable arriba del 4\% anual, en un ambiente de bajas tasas anuales de inflación (3-5\%), tasas de interés competitivas (tasa de interés sobre los depósitos a término fijo DTF en el rango del 4-6\% efectivo anual), reducción sostenida de la tasa de desempleo (16 a 11\%) y de revaluación sostenida del peso. El buen desempeño relativo de la economía se atribuye a la continuidad en las políticas monetarias, fiscales, y comerciales y al establecimiento de metas de largo plazo que apuntan a darle mayor ritmo de crecimiento y de estabilidad a la economía en el futuro.

Como lo documenta el estudio de Ramírez, et al. (2007) la agricultura en general, y el arroz en particular, han recuperado los niveles de protección que tenían antes de la apertura comercial mediante mecanismos como: bandas de precios, aranceles y contingentes de importación sujetos a la absorción de la cosechas. El fortalecimiento de las cadenas productivas y de los acuerdos de competitividad, la apertura de nuevos mercados internacionales mediante acuerdos de comercio, la mayor disponibilidad de recursos de presupuesto y crédito para incentivar y apoyar directamente a la agricultura y mantener el ingreso de los productores (a través de instrumentos como la ciencia y tecnología, el Incentivo a la Capitalización Rural ICR, Agro Ingreso Seguro AIS, el Fondo de Financiamiento Agropecuario FINAGRO, precios mínimos o de referencia, protección de precios con mecanismos bursátiles, entre otros) han generado un ambiente de expectativas favorables para el desarrollo de mercados de capitales. 


\subsection{Desarrollo y organización del mercado de físicos}

El mercado de físicos del arroz debe, a su vez, disponer de una organización y nivel de desarrollo mínimo que provea soporte a las transacciones y operaciones del mercado de futuros y contribuya a darle profundidad y liquidez.

El Cuadro 8 resume las principales fortalezas y debilidades del mercado de físicos del arroz para soportar un mercado de futuros y derivados, evaluadas mediante reuniones focales y entrevistas en profundidad con agricultores, industriales y expertos de diferentes empresas e instituciones.

Cuadro 8. Fortalezas y debilidades existentes en el mercado de físicos del arroz

\begin{tabular}{|c|c|c|}
\hline Condición & Fortalezas & Debilidades \\
\hline $\begin{array}{l}\text { - Tipificación y } \\
\text { normalización del } \\
\text { producto }\end{array}$ & $\begin{array}{l}\text { - Normas técnicas conforme a } \\
\text { los estándares internacionales } \\
\text { NTC-671 (Arroz blanco) NTC- } \\
519 \text { (Arroz cáscara seco) }\end{array}$ & $\begin{array}{l}\text { - Las normas se aplican de } \\
\text { acuerdo a la situación del } \\
\text { mercado (oferta-demanda) } \\
\text { - Análisis subjetivos de } \\
\text { laboratorio } \\
\text {-Faltan laboratorios pares de } \\
\text { referencia para análisis calidad } \\
\text { arroz paddy verde } \\
\text {-Normas y protocolos } \\
\text { técnicos necesitan revisarse y } \\
\text { actualizarse } \\
\text {-No hay normas para arroz } \\
\text { paddy verde }\end{array}$ \\
\hline $\begin{array}{l}\text { - Sistemas } \\
\text { eficientes de } \\
\text { resolución de } \\
\text { conflictos }\end{array}$ & $\begin{array}{l}\text { - BMC tiene experiencia en } \\
\text { resolución de conflictos a } \\
\text { través de la Cámara Central de } \\
\text { Riesgos de Contraparte CCRC } \\
\text { y de la Cámara Arbitral } \\
\text { - La conciliación y el } \\
\text { arbitramento institucional } \\
\text { está consagrado por ley (Ley } \\
\text { 23/1991) }\end{array}$ & $\begin{array}{l}\text { - Se debe contar con un } \\
\text { centro específico de resolución } \\
\text { de conflictos y arbitramento } \\
\text { dentro de la Cámara Arbitral } \\
\text { para el sector arrocero conforme } \\
\text { a lo dispuesto por la Ley }\end{array}$ \\
\hline
\end{tabular}




\begin{tabular}{|c|c|c|}
\hline $\begin{array}{l}\text { - Sistemas de } \\
\text { información } \\
\text { públicos de } \\
\text { mercados }\end{array}$ & $\begin{array}{l}\text { - Existe información de } \\
\text { precios históricos públicos } \\
\text { y privados: DANE, SIPSA, } \\
\text { FEDEARROZ, BMC-SIVIC }\end{array}$ & $\begin{array}{l}\text { - No existe un Sistema de } \\
\text { Información de Mercados (SIM) } \\
\text { en operación } \\
\text { - No hay disponibilidad de } \\
\text { información de precios y } \\
\text { mercados en tiempo real } \\
\text { - Se carece de información } \\
\text { confiable sobre cambios de } \\
\text { inventarios }\end{array}$ \\
\hline $\begin{array}{l}\text { - Esquemas } \\
\text { competitivos de } \\
\text { negociación e } \\
\text { intermediación }\end{array}$ & $\begin{array}{l}\text { - Se tiene experiencia en } \\
\text { operaciones forward a través } \\
\text { de la BMC } \\
\text { - Existen experiencias de } \\
\text { agricultura por contrato } \\
\text { - Hay experiencias de } \\
\text { programas integrados de } \\
\text { producción y mercadeo } \\
\text { de arroz con pequeños } \\
\text { productores }\end{array}$ & $\begin{array}{l}\text { - Mercado industrial y de } \\
\text { provisión de insumos con } \\
\text { estructura oligopólica y } \\
\text { oligopsónica } \\
\text {-Débil coordinación e } \\
\text { integración vertical y horizontal } \\
\text {-Mayoría de agricultores tienen } \\
\text { bajo poder de negociación } \\
\text { - Contratos de compra - venta } \\
\text { informales y no estandarizados }\end{array}$ \\
\hline $\begin{array}{l}\text { - Infraestructura } \\
\text { adecuada de } \\
\text { almacena-miento, } \\
\text { acopio y acondicio- } \\
\text { namiento }\end{array}$ & $\begin{array}{l}\text { - Infraestructura de } \\
\text { acopio y procesamiento y } \\
\text { almacenamiento apropiados } \\
\text { en zonas de producción } \\
\text { excedentarias }\end{array}$ & $\begin{array}{l}\text { - Alta concentración de los } \\
\text { sistemas de acopio, secamiento } \\
\text { y almacenamiento en la } \\
\text { industria } \\
\text { - Altas pérdidas y altos costos } \\
\text { de transporte arroz paddy verde } \\
\text { - Altos costos de } \\
\text { almacenamiento, } \\
\text { acondicionamiento y transporte } \\
\text { de paddy seco y blanco } \\
\text { - Falta infraestructura } \\
\text { pública de riego y drenaje, } \\
\text { electrificación y vías en zonas } \\
\text { de arroz secano } \\
\text { - No hay sistemas de secamiento } \\
\text { y almacenamiento en fincas }\end{array}$ \\
\hline $\begin{array}{l}\text { - Sistema de } \\
\text { seguros de } \\
\text { producción }\end{array}$ & $\begin{array}{l}\text { - Seguro agropecuario para } \\
\text { cubrir riesgos climáticos } \\
\text { (inundaciones, sequías, vientos } \\
\text { fuertes) }\end{array}$ & $\begin{array}{l}\text { - No se aplica en arroz de } \\
\text { secano } \\
\text { - Muy baja utilización en arroz } \\
\text { riego }\end{array}$ \\
\hline
\end{tabular}




\begin{tabular}{|l|l|l|}
\hline & - Créditos asociativos & - Alto costo y dificultad de \\
& - Créditos de fomento (AIS, & acceso al crédito formal por \\
& ICR, FINAGRO) & agricultores \\
- Sistemas y & - Reporto sobre Certificados & - Alto riesgo de contraparte \\
mecanismos de & de Depósito de Mercancías & - Muy fácil acceso al crédito \\
crédito formal & CDM & informal de procesadores y \\
& - Reporto sobre facturas & casas comerciales \\
& cambiarias de compra-venta & - Agricultores sin acceso a \\
& - Existencia del Fondo & CDM \\
& Agropecuario de Garantías & \\
\hline
\end{tabular}

Fuentes: Ramírez, et. al. (2008) y Martínez et .al. (2007).

Las debilidades del mercado de físicos enumeradas requieren ser superadas a fin adecuar el mercado a los sistemas, infraestructura y mecanismos de negociación requeridos para la operación y funcionamiento de contratos de futuros en el mercado de la BMC. En todos los casos, los procesos de integración regional o subregional a través de tratados de libre comercio, requieren de sistemas transaccionales regulados y transparentes una razón adicional para promover el desarrollo de los mercados de contado del arroz.

\subsection{Profundidad y liquidez del mercado de la BMC para arroz}

La profundidad y liquidez de los mercados es un requisito tanto para el mercado de físicos como el de futuros. La profundidad del mercado bursátil la determina el volumen potencial de contratos de futuros y de opciones en arroz paddy seco ó blanco que se podrían generar en la BMC. La liquidez la determina el número potencial de agentes del mercado bursátil para arroz que se pudiera agrupar (coberturistas, inversionistas ó especuladores y de arbitradores). Estos parámetros dependen en buena parte de la profundidad (volumen de arroz y número de transacciones) y de liquidez (número de compradores y vendedores) en el mercado de físicos del arroz

Según Martínez et al. (2007), el arroz ha sido uno de los productos líderes en las operaciones bursátiles de la BMC desde su inicio en 1979. La ley 101/1993, estimuló las transacciones de arroz realizadas a través de las bolsas de productos al quedar exentas de la retención en la fuente. Esta medida ha permitido registrar gran parte (30 a 60\%) de las operaciones anuales convenidas de compra venta del arroz paddy verde, seco, y arroz blanco en el mercado por fuera de rueda (OTC). También, acopiar información referente a precios por zonas, cantidades y calidades para los diferentes tipos de arroz: paddy verde, paddy seco, arroz blanco en bulto, arroz blanco empaquetado, arroces procesados y subproductos. 
Con la creación del mercado de compras públicas por medio de subastas de la Bolsa, se dio inicio a las operaciones de físicos (disponibles y de contratos anticipados ó forward) en el mercado abierto de la Bolsa (OMA). Los contratos anticipados de arroz paddy seco fueron las primeras operaciones de físicos realizadas en el mercado abierto de la Bolsa. A su vez, las operaciones REPO sobre los Certificados de Depósito de Mercancías CDM representados en arroz paddy seco y arroz blanco, fueron las operaciones pioneras realizadas sobre instrumentos financieros en el mercado abierto de la Bolsa. Estas se iniciaron en el 2003 y fueron facilitadas por el incentivo al almacenamiento de arroz.

El crédito asociativo, el concepto de proyectos productivos integrados al mercado y los mecanismos de agricultura por contrato orientados al desarrollo de cadenas productivas desde el 2003, impulsaron los contratos anticipados de compra-venta de la cosecha o de entrega futura forward en arroces paddy verde registrados en la Bolsa, debido a que, el contrato garantiza la liquidez del mercado y se constituye en la fuente de pago de los créditos asociativos. Mientras estos contratos representan un avance significativo en el desarrollo del mercado de físicos para los agricultores estos no son estandarizados y llenan los requerimientos para convertirse en contratos de futuros.

La viabilidad financiera de un mercado de contratos de futuro interno depende, entre otros factores, del tamaño del mercado de físicos de arroz que es el siguiente (FEDEARROZ, 2008):

- Agricultores (No): 21,800 (primer semestre 2007)

- Unidades de producción (No): 26,773 (primer semestre 2007)

- Industriales (No): 152 (85 activos, 2007)

- Producción de arroz paddy verde $\left(\mathrm{m}^{3}\right)$ : 2,231,360 (promedio 2007-2009)

- Valor producción arroz paddy verde equivalente (US\$): 1,006,224,617 (promedio 2007-2009 a precios del 2011).

En concepto de los expertos consultados y debido a la existencia de asimetrías en los apoyos y las condiciones de producción de los competidores extranjeros tales como: mayor infraestructura, subsidios y apoyos directos entre otros factores los productores nacionales de arroz se encuentran en desventajas para competir en el mercado mundial. Por otra parte, las estructuras oligopsónicas y oligopólicas del mercado interno no permiten una mayor liquidez y competencia.

Por esas razones se considera que el mercado de físicos nacional puede carecer de suficiente profundidad para hacer viable un mercado local de futuros y opciones para la cobertura de riesgos de precios. Sin embargo, es recomendable que esta alternativa se evalúe en términos de la factibilidad técnica y viabilidad financiera para crear un mercado de futuros y opciones para arroz en el país. 
Otra alternativa es hacer la transferencia de riesgos de precios a los mercados globales de arroz de acuerdo a los procesos de globalización y los desarrollos tecnológicos que permiten ampliar el ámbito de las bolsas de productos básicos.

\subsection{Correlación de precios domésticos del arroz y el precio en el mercado internacional}

La liberación del comercio mundial y los sistemas y tecnologías de informática y de telecomunicaciones han propiciado una mayor competencia comercial traducida en mayor incertidumbre sobre los precios. También han favorecido el desarrollo de mercados globales de instrumentos de coberturas de riesgos. Según Fleisher (1990) para hacer financieramente viables las coberturas de riesgos en mercados de futuros y derivados globales como las Bolsas de productos agropecuarios de New York ó de Chicago, por ejemplo, los precios domésticos del producto físico deben ser menores que el mercado internacional y registrar una alta correlación positiva con los precios del producto en los mercados de Estados Unidos

La correlación existente entre los precios internacionales y el precio interno del arroz paddy seco se estimó en +0.77 lo cual satisface este requerimiento. Las mejoras en la eficiencia de producción y productividad del cultivo han permitido que los precios del arroz blanco al consumidor caigan en términos nominales y reales. Sin embargo, los precios internos del arroz en Colombia aún resultan ser significativamente más altos que los precios en el mercado mundial (Estados Unidos y Tailandia) lo cual hace que el riesgo de base para hacer las coberturas pueda ser muy alto ${ }^{12}$. Por lo tanto, se plantea que este riesgo debe evaluarse en detalle como requisito para establecer la viabilidad financiera de instrumentar coberturas de riesgos de precios internos del arroz en mercados globales líquidos y profundos de futuros y derivados.

En los mercados globales se opera el contrato de futuros y opciones de arroz en el Chicago Board of Trade (CBOT). Este contrato se ha consolidado debido a su liquidez y profundidad. En consecuencia este debería ser el mercado de referencia natural para la operatoria en los mercados locales. Los contratos de futuros y opciones de arroz cáscara de la CBOT operan desde 1994 y tienen entre otras las siguientes especificaciones más relevantes:

- Volumen del contrato: 2.000 CWT (90.72 ton por contrato)

- Meses de contrato: Septiembre, Noviembre, Enero, Marzo, Mayo y Julio

12 En este caso, la base es la diferencia entre el precio presente en el mercado de físicos doméstico y el precio en el mercado de futuros en el exterior. El riesgo de base es la probabilidad de que el precio de futuros en el exterior sea menor que el precio en el mercado doméstico La base está conformada por varios factores; precio interno, costo de transporte, costos de almacenamiento, costos financieros, seguros, costos de operación y tasa de cambio. 
- Fluctuación máximo precio: 0,03 USD/libra (600 USD por contrato)

- Fluctuación mínimo precio: 0,005 USD/libra (10 USD por contrato)

- Incremento del precio de ejercicio: 0,10 USD por libra

- Estándar de entrega: Arroz cáscara grano largo con rendimiento industrial no inferior al $65 \%$ y con descuento por cada punto porcentual que exceda $15 \%$ de granos quebrados.

\section{Formulación de líneas de acción}

Esta sección delinea estrategias e instrumentos que permitan mitigar los riesgos de mercado (precios), crédito y liquidez asociados, dadas las condiciones del mercado de físicos y el ambiente regulatorio y operacional del mercado bursátil de la BMC. En orden de importancia se propone:

\subsection{Promover e implementar esquemas para que los agricultores de arroz mantengan el control del producto físico antes de salir al mercado}

Este aspecto es una condición sine qua non para la administración de los riesgos presentes de volatilidad de precios incluido su acceso a instrumentos basados en el mercado bursátil de la BMC. Esta estrategia les debe permitir a los agricultores: a) darle valor agregado al arroz; b) facilitar el acceso a financiamiento y crédito de fuentes no convencionales (por ejemplo, a través de operaciones Repo sobre CDM) y c) beneficiarse del incentivo actual al almacenamiento de arroz.

Con esta acción se trata de otorgarle un mayor poder de negociación a los agricultores en el mercado de físicos del paddy seco mediante tecnologías apropiadas de secamiento que contribuyan a reducir las pérdidas físicas actuales de arroz y de calidad del grano húmedo y aumentado sus ingresos. Por otro parte, propender por la estabilidad de los precios en este segmento de la cadena productiva.

Esta estrategia involucra dos opciones: a) el diseño, prueba, validación y diseminación de tecnologías de secamiento de arroz paddy verde en fincas adaptadas a las condiciones del medio ambiente, dotación de recursos y requerimientos de calidad molinera, culinaria y nutricional del mercado y/o; b) el fomento al establecimiento de servicios de secamiento y almacenamiento de arroz, donde los agricultores puedan contratar estos servicios sin perder la posesión del arroz paddy seco.

5.1.1 Secamiento del arroz paddy verde en fincas: esta actividad es una práctica generalizada de manejo del cultivo de arroz en post cosecha en los países productores 
de las zonas templadas del mundo y del trópico asiático y africano. Un estudio por Courtois (1996) estimó que, entre el 70 y 90\% del arroz cosechado en Asia donde se produce el $94 \%$ del arroz mundial, se retenía en las fincas mediante diferentes sistemas convencionales de secamiento al sol, de aireación durante el almacenamiento, y sistemas no convencionales. Un sinnúmero de prototipos no convencionales de secamiento de arroz paddy verde se han desarrollado con el principio de convección forzada por entidades como el Instituto Internacional del Arroz IRRI. Su utilización por los agricultores en el mundo ha sido creciente.

No así en las regiones tropicales latinoamericanas y del Caribe, en donde la industria molinera ha asumido históricamente la responsabilidad del secamiento y almacenamiento del arroz paddy en un mercado que es típicamente de vendedores de arroz paddy verde. En Colombia, la conveniencia de que los agricultores dispongan de facilidades de secamiento y almacenamiento de arroz en post cosecha como esquema para modernizar y desarrollar el mercado de físicos no ha estado manifiesto ni en los programas de política sectorial ni de las instituciones de investigación y desarrollo tecnológico del cultivo.

5.1.2 Secamiento del arroz en plantas de servicios de secamiento: una alternativa complementaria para darle mayor poder de negociación al agricultor es la posibilidad de acceder a servicios contratados de secamiento y almacenamiento, una práctica que se ha extendido en algunos países debido a ventajas como: la facilidad de control de los parámetros del secamiento; el aseguramiento de la calidad molinera del arroz paddy seco y menores costos unitarios del proceso por economías de tamaño de la operación. Esta opción resulta atractiva si se tiene en cuenta que, la mayoría de los agricultores de arroz mecanizado de Colombia, cultivan pequeñas extensiones y cerca de la mitad son arrendatarios con escaso capital de inversión en maquinaria y equipo ${ }^{13}$. La distancia de las fincas a las plantas de secamiento (altos costos de transporte) y la falta de organización de los pequeños agricultores en asociaciones locales que faciliten el acceso de los mismos a los apoyos del Estado (incentivo al almacenamiento, créditos asociativos, fondo de garantías agropecuarias, entre otros) podrían ser factores que afecten la viabilidad financiera de las plantas, en particular en aquellas zonas de producción más aisladas del país de los Llanos Orientales y la Costa Norte.

\subsection{Promover el mayor desarrollo del mercado de físicos del arroz}

El desarrollo de los mercados de contado de los productos agropecuarios ha sido uno de las estrategias misionales de la BMC a fin de hacer los mercados de productos más transparentes, profundos y dinámicos. La curva de experiencia acumulada por

13 Según el tercer censo nacional arrocero en el $83.6 \%$ de las fincas arroceras se sembraban menos de 10 has de arroz. El $71.4 \%$ de estas unidades de producción eran operadas por arrendatarios (FEDEARROZ, 2008). 
la BMC desde 1979 y la reciente normatividad le permiten a la Bolsa especializar los mercados de físicos para facilitar la transparencia de las negociaciones mediante: normas de calidad estandarizadas, empleo de contratos estandarizados, sistemas de resolución de conflictos y descubrimiento de precios en los mercados abierto y OTC.

La Bolsa además, ha generado y diseminado información sobre las transacciones y productos agropecuarios negociados aprovechando los avances en tecnología y comunicaciones; hace uso intensivo del recurso humano especializado (miembros y corredores de Bolsa); capacita a los agentes del mercado y desarrolla nuevos productos bursátiles y servicios. En conjunto, estas acciones le permiten a los agricultores, industriales y distribuidores: a) negociar los productos agropecuarios con anterioridad a las cosechas y b) eliminar la necesidad de llevar el producto físico al mercado. Con esta experiencia, la BMC dispone de los elementos para fortalecer las operaciones fuera de rueda (OTC) y de los mercados de físicos especializados acordes a las necesidades y condiciones del mercado.

Los mercados especializados de físicos como el MCP, las subastas o martillos organizados por la BMC para cubrir las deficiencias de liquidez en los mercados regionales o subregionales son una oportunidad especialmente para el mercado del arroz porque permitirían formalizar los flujos de productos de los países vecinos.

De otra parte, los instrumentos financieros derivados ${ }^{14}$ estructurados por la BMC han cumplido una función de financiamiento para el sector productivo agropecuario a costos competitivos. Así mismo, han ofrecido al mercado de capitales nuevas alternativas de inversión. El marco normativo abrió oportunidades para desarrollar novedosos instrumentos y cubrir las deficiencias evidenciadas en cuanto a las coberturas de riesgos especialmente de crédito.

\subsection{Diseñar e implementar estudios de factibilidad técnica $y$ viabilidad financiera para hacer coberturas de riesgos de precios en un mercado de futuros y derivados local a través de la BMC y/o en el mercado de la CBOT (Estados Unidos).}

5.3.1 Estructuración de un instrumento financiero derivado explicito mediante un contrato forward FFD (forward full delivery) para ser operado en el mercado OTC y registrado en la $B M C^{15}$

14 Los instrumentos financieros son contratos que dan origen a activos financieros en una entidad y a un pasivo o a un instrumento de capital ó patrimonio en otra entidad.

15 Existen dos tipos de operaciones forward de acuerdo a su modalidad de liquidación: con entrega FDF (full delivery forward) y sin entrega NDF (non delivery forward). El primero es un contrato de compra-venta a la medida (no estandarizado) suscrito en el presente con obligaciones y derechos de entrega y pago en el futuro. 
Dada la curva de experiencia de la BMC en el mercado de físicos y de derivados financieros este tipo de contrato debe contribuir a: a) mitigar los riesgos de liquidez de los agricultores, industriales y distribuidores en el mercado de físicos; b) desarrollar e instrumentar derivados implícitos (valores negociables); c) desarrollar instrumentos de coberturas de riesgos de crédito de contraparte a través de swaps; e) servir de colateral para cubrir el riesgo residual de crédito de contraparte en los créditos asociativos; f) tomar coberturas en el mercado de derivados para cubrir los riesgos de mercado; g) tomar coberturas para los riesgos agroclimáticos y h) generar liquidez en el mercado primario de derivados.

5.3.2 Estudio de factibilidad para desarrollar derivados explícitos e implícitos ${ }^{16}$ en el mercado OTC y mercado abierto de la BMC para el arroz paddy seco y arroz blanco.

Los resultados del estudio evidencian que, en Colombia, existe la posibilidad de crear derivados explícitos e implícitos en los mercados bursátiles OTC y abierto de la BMC, como se muestra en al Cuadro 9.

Cuadro 9. Alternativas para desarrollar derivados explícitos e implícitos en el mercado OTC y el mercado abierto de la BMC

\begin{tabular}{|c|c|c|}
\hline Instrumento & Riesgo Cubierto & Operatoria \\
\hline \multicolumn{3}{|c|}{ Derivados Explícitos } \\
\hline Forward Non Delivery & Mercado & $\begin{array}{c}\text { Cobertura precio, operado } \\
\text { en la BMC }\end{array}$ \\
\hline SWAPS & Crédito & $\begin{array}{c}\text { Intercambio de flujos de } \\
\text { efectivo, operado en la } \\
\text { BMC }\end{array}$ \\
\hline Valores Negociables & Derivados Implícitos & $\begin{array}{c}\text { Negociaciones de } \\
\text { derechos en el mercado } \\
\text { abierto de la BMC }\end{array}$ \\
\hline
\end{tabular}

Fuente: Martínez et al. (2007)

16 Los derivados implícitos son aquellos componentes de un contrato que no originan un instrumento financiero derivado por sí mismos. Sin embargo, los riesgos implícitos generados o cubiertos por esos componentes, difieren en sus características económicas y riesgos, de los del contrato anfitrión y, por consiguiente, resultan en un comportamiento y características similares a los que presenta un instrumento financiero derivado común ó explícito. 
Estos instrumentos permiten: a) cubrir el riesgo de mercado inherente a las bajas de los precios; b) trasladar el riesgo derivado de la fluctuación de los precios; c) tomar la cobertura sin costo para el agricultor, industrial y distribuidor; d) cubrir los riesgos inherentes al crédito de contraparte; y, e) apalancar recursos para financiar las actividades y procesos productivos y de distribución.

5.3.3 Estudio de factibilidad técnica y viabilidad financiera del desarrollo de un mercado de derivados local: futuros y opciones: el objetivo de este estudio es evaluar la factibilidad operativa y financiera de desarrollar un contrato de futuros y opciones de arroz paddy seco y arroz blanco en la BMC. Los componentes de este estudio deben hacer referencia a: a) el análisis fundamental y técnico del mercado de físicos; b) la profundidad, liquidez y administración del mercado de físicos y del mercado de futuros y opciones; c) el impacto potencial del mercado de futuros y opciones sobre el mercado de físicos o de contado; e) las posibilidades de combinar posiciones de contado (en efectivo) con las de futuros y opciones y f) la identificación de estrategias básicas y avanzadas para usar las opciones en el establecimiento de precios "piso" para los agricultores, industriales y distribuidores del arroz y un precio "techo" para usuarios del arroz paddy seco y blanco.

El estudio de factibilidad debe estructurar un contrato de futuros en arroz paddy seco y arroz blanco y un contrato de opciones sobre el contrato de futuros en arroz cáscara ó blanco.

5.3.4 Estudio de factibilidad para el desarrollo de un sistema de coberturas en los mercados globales: el propósito de este estudio es explorar la factibilidad operativa y financiera de desarrollar un sistema para tomar coberturas de riesgos de precios del arroz paddy seco y arroz blanco a través de futuros y opciones en la CBOT. Los componentes del estudio son esencialmente similares a los presentados para el estudio anterior. De especial importancia son: la determinación del grado de convergencia de los precios y la identificación del riesgo de base y su posible comportamiento. Estos parámetros son críticos para definir la viabilidad y éxito de las coberturas del riesgo de precios en el mercado internacional. 


\section{REFERENCIAS BIBLIOGRÁFICAS}

Anderson, J. R., Dillon, J. L., and Hardaker, J. B. (1977). Agricultural Decision Analysis. Ames: Iowa State University Press. 315p.

Anderson, K. B., and Mapp, H. P. (1977). Risk Management Programs in Extension. Journal of Agricultural and Resource Economics 21 (2), 31-38.

Barry, P J., and. Baker, C. B. (1984). Financial Responses to Risk in Agriculture. In: Risk Management in Agriculture. Ed. Peter J. Barry. Iowa State University Press: Ames, Iowa. pp. 183-199.

Black, Fischer. (1976). The Pricing of Commodity Contracts. Journal of Financial Economics 3, 167-179.

Boehlje, M. D., and Trede, L. D. (1977). Risk Management in Agriculture. Journal of the American Society of Farm Managers and Rural Appraisers 41 (1), 20-29.

Courtois, F. (1996). Non-conventional grain drying technology. In: Proceedings of an International Conference on Grain Drying in Asia. FAO Regional Office for Asia and the Pacific, Bangkok, Thailand, 17-20 October 1995. Champ, B.R., Highley, E. and Johnson, G.I., eds. ACIAR Proceedings No. 71. pp. 229-235. Canberra, Australia: ACIAR.

Federación Nacional de Arroceros FEDEARROZ. (2007). Censo Nacional Arrocero 2006. Bogotá, Colombia.

Fleisher, Beverly. (1990). Agricultural Risk Management. Boulder and London: Lynne Rienner Publishers, Inc. 288p.

Hardaker, J. B., Ruud, B. M. H., and Anderson, J. R. (1997). Coping With Risk in Agriculture. New York: CAB International, 234p

Jayne, T. and B. Myers. (2004). Managing Food Price Instability and Risk in Low Income Countries: The Problem and Emerging Policy Options. Department of Agricultural Economics. Draft. East Lansing: Michigan State University.

Lutgen, L.H. and Todd, L.A. (1997). An Introduction to grain options on futures contracts. University of Nebraska, Cooperative Extension Institute of Agriculture and Natural Resources. NebGuide G85-770-A. Lincoln, Nebraska. 12p.

Mapp, H. P., Hardin, M. L , Walker, O. L. and Persaud, T. 1979. Analysis of Risk Management Strategies for Agricultural Producers. American Journal of Agricultural Economics 61 (3), 1071-1077.

Martínez, E., Ramírez, A., Rivas, L., M. A. Rodríguez, Gutiérrez, N., y E. García. 2007. Caracterización de los mercados bursátiles y de los mecanismos para la administración de riesgos para la cadena arrocera de Colombia. Informe final. Proyecto colaborativo FLAR-FEDEARROZ-CFC-CIAT. Cali, Colombia. 53p. 
Miller, L H., Ellinger, P. N., Barry, P.T, and Lajili, K. 1993. Price and Nonprice Management of Agricultural Credit Risk. Agricultural Finance Review 53, 28 41.

Purcell, W.D. and Koontz, S.R. 1999. Agricultural Futures and Options: Principles and Strategies. Prentice Hall: Upper Saddle River, New Yersey. 399p.

Purcell, W. D. 1979. Agricultural Marketing: Systems, Coordination and Futures Prices. Reston Publishing Company: Reston, Virginia. 472p.

Ramírez, A., Martínez E., and L. Rivas. 2008. Diagnostic of Financial Gaps in the Rice Sector of Argentina, Colombia and Costa Rica. Project Completion Report. CIAT Cali, Colombia. 55p.

Ramírez, A., Rivas, L., Martínez, E. Gutiérrez, N., y E. García. 2007. Estructura, conducta y desempeño de la cadena arrocera de Colombia. Informe final. Proyecto colaborativo FLAR-FEDEARROZ-CFC-CIAT. Cali, Colombia. 131p.

Tweeten, E. A. 1979. Farm Policy. University of Nebraska Press: Lincoln, Nebraska. $578 \mathrm{p}$. 